\title{
Residência Pedagógica e o ensino remoto: desafios e perspectivas na ótica de preceptores
}

\author{
Pedagogical Residency and remote teaching: challenges and perspectives in the view of basic \\ education teachers participating in the program
}

Residencia Pedagógica y telepedagogía: retos y perspectivas a la vista de los docentes de educación básica que participan en el programa

\section{Resumo}

Esse trabalho tem como objetivo conhecer percepções, sentimentos, habilidades e desafios de preceptores vinculados ao Programa Residência Pedagógica (IFPI) na condução das atividades docentes e orientação frente às exigências impostas pelo ensino remoto. A pesquisa é básica, de natureza observacional com abordagem quali-quantitativa. Toda a pesquisa ocorreu de forma não presencial e utilizou ferramentas de comunicação digital no trato aos participantes. A efetivação da participação ocorreu por meio da concordância a Termo de Consentimento Livre e Esclarecido que garantiu entre outras coisas o anonimato, retirada dos dados da pesquisa a qualquer momento anterior à publicação, bem como a divulgação científica dos resultados. Para coleta, utilizou-se um questionário semiestruturado produzido por meio da plataforma Google Forms, subdividido em quatro seções, sendo a primeira responsável pela caracterização do perfil, a segunda relacionada a percepção dos preceptores quanto a realização do programa Residência Pedagógica, uma relacionada ao uso de tecnologias digitais, e por fim uma relacionada aos sentimentos associados ao ensino remoto. Constatamos que apesar das dificuldades apresentadas e do difícil momento que vivenciamos, as experiências relacionadas ao ensino remoto vêm proporcionando o desenvolvimento e aprimoramento de diversas habilidades docentes pelos preceptores. Além disso, os participantes também relatam que os aprendizados construídos nos dois primeiros módulos da Residência Pedagógica servirão de base para novas estratégias a serem utilizadas nas aulas presenciais. Por fim, ressaltamos a importância de outros estudos que demonstrem os impactos do ensino remoto na educação básica e as transformações metodológicas por ele estimuladas a serem vivenciadas na educação presencial. 
Palavras-chave: Aulas remotas; Estratégias metodológicas; Ferramentas digitais de ensino.

\begin{abstract}
This work aims to understand the perceptions, feelings, skills and challenges of preceptors linked to the Pedagogical Residency Program (IFPI) in conducting teaching activities and providing guidance to the demands imposed by remote learning. The research is basic, observational with a quali-quantitative approach. The entire research occurred remotely and used digital communication tools when dealing with the participants. The effective participation by occurrence through the agreement to the Informed Consent Term, which guaranteed, among other things, anonymity, removal of research data at any time before publication, as well as the scientific dissemination of the results. For the collection, we used a semi-structured questionnaire produced through the Google Forms platform, subdivided into four, the first being responsible for the characterization of the profile, the second related to the perception of preceptors regarding the realization of the Pedagogical Residency program, a relation to the use of digital technologies, and finally one related to the feelings associated with remote learning. We found that despite the difficulties and the difficult time we live, as experiences related to remote teaching providing the development and improvement of teaching skills by preceptors. Additionally, the participants also report that the learning built in the first two modules of the Pedagogical Residency will serve as a basis for new strategies to be used in classroom classes. Finally, we emphasize the importance of other studies that demonstrate the impacts of remote education on basic education and the methodological changes it encourages to be experienced in face-to-face education.
\end{abstract}

Keywords: Remote classes; Methodological strategies; Digital teaching tools.

\title{
Resumen
}

Este trabajo tiene como objetivo comprender las percepciones, sentimientos, habilidades y desafíos de los preceptores vinculados al Programa de Residencia Pedagógica (IFPI) en la realización de actividades docentes y en la orientación a las demandas que impone el aprendizaje a distancia. La investigación es básica, de naturaleza observacional con un enfoque cuali-cuantitativo. Toda la investigación se llevó a cabo de forma presencial y se utilizaron herramientas de comunicación digital al tratar con los participantes. La participación se realizó mediante la aceptación del Formulario de Consentimiento Informado, que garantizaba, entre otras cosas, el anonimato, la eliminación de los datos de la investigación en cualquier momento previo a la publicación, así como la difusión científica de los resultados. Para la recolección se utilizó un cuestionario semiestructurado elaborado a través de la plataforma Google Forms, subdividido en cuatro apartados, siendo el primero el responsable de la caracterización del perfil, el segundo relacionado con la percepción de los preceptores sobre la realización del programa de Residencia Pedagógica, uno relacionado con el uso de tecnologías digitales y, finalmente, otro relacionado con los sentimientos asociados al aprendizaje a distancia. Descubrimos que a pesar de las dificultades presentadas y el momento difícil que estamos atravesando, las experiencias relacionadas con la enseñanza a distancia han proporcionado el desarrollo y mejora de diversas habilidades docentes por parte de los preceptores. Además, los participantes también informan que el aprendizaje construido en los dos primeros módulos de la Residencia Pedagógica servirá como base para nuevas estrategias que se utilizarán en las clases presenciales. Finalmente, destacamos la importancia de otros estudios que demuestren los impactos de la educación a distancia en la educación básica y los cambios metodológicos que promueve vivir en la educación presencial.

Palabras clave: Clases remotas; Estrategias metodológicas; Herramientas didácticas digitales.

\section{Introdução}

No início de 2018, foi lançado no Brasil o Programa de Residência Pedagógica (PRP) do Ministério da Educação (MEC), por meio do edital 6/2018 da Coordenação de Aperfeiçoamento de Pessoal de Nível Superior - CAPES (Brasil, 2018). O programa integra a Política Nacional de Formação de Professores do MEC e tem por finalidade promover a experiência de regência em sala de aula a discentes da segunda metade dos cursos de licenciatura (Brasil, 2020).

Em janeiro de 2020 foi lançado o edital 1/2020 pela CAPES que tinha como objetivo selecionar, no âmbito do PRP, até 250 Instituições de Ensino Superior (IES) brasileiras para implementação de projetos inovadores que estimulem articulação entre teoria e prática nos cursos de licenciatura, conduzidos em parceria com as redes públicas de educação básica. A aprovação da IES no referido edital garantia a concessão de bolsas a residentes, professores da educação básica (preceptores) e docentes orientadores vinculados às IES beneficiadas.

O Instituto Federal de Educação, Ciência e Tecnologia do Piauí (IFPI) foi uma das instituições contempladas pelo projeto, e suas atividades iniciaram em outubro de 2020 com previsão de término para março de 2022. O projeto RP-IFPI conta com a participação de 13 núcleos, distribuídos em sete municípios piauienses, sendo eles: Angical, Floriano, Parnaíba, Picos, 
Piripiri, Teresina e Uruçuí, contemplando discentes dos cursos de Licenciatura em Biologia, Física, Informática, Matemática e Química.

O período de início das atividades da PRP-IFPI (2020-2022) foi marcado pelo regime de aulas remotas nas diversas escolas da educação básica participantes do programa, como definido pela portaria SEDUC-PI/GSE nº 503/2020 (Seduc, 2020). O cenário de aulas remotas impôs novos desafios a todos os atores do PRP, inclusive aos preceptores, que tem como atribuições orientar os residentes na elaboração de seus planos de aula e na execução da prática pedagógica, bem como orientar as atividades na escola (Brasil, 2019), o que exigiu total adaptação ao modelo remoto.

Para Rosseto et al. (2020), a transição para o ensino de forma remota foi imprescindível para minimizar os impactos à educação em decorrência da falta de aulas presenciais. Desse modo, essa modalidade de ensino em ambiente virtual é desafiante e requer por parte do docente reflexão constante e criatividade (Oliveira \& Madureira, 2020), ao mesmo tempo em que professores e alunos são levados a praticar um reaprendizado em ensinar e aprender (Rosseto et al., 2020).

Frente a contextualização até aqui exposta, cabe discutir a ótica dos preceptores (PRP-IFPI) sobre a execução do programa de forma remota e os desafios da prática pedagógica frente ao uso das Tecnologias Digitais de Comunicação e Informação (TDIC) em tempos de pandemia. Além disso, quais as percepções, demandas e sentimentos associados ao ensino remoto na execução de suas atividades escolares e de orientação dos residentes?

Destacamos que o conhecimento das perspectivas de preceptores frente aos desafios por eles enfrentados na Educação Básica e na condução de suas atividades associadas ao PRP, se mostram como uma estratégia diagnóstica que poderá contribuir com a garantia de qualidade educacional aos alunos da educação básica e qualidade na formação docente de residentes. Dessa forma, esse trabalho tem como objetivo conhecer percepções, sentimentos, habilidades e desafios de preceptores vinculados ao Programa Residência Pedagógica (IFPI - 2020/2022) na condução de suas atividades docentes e de orientação frente às exigências impostas pelo ensino remoto.

\section{Metodologia}

A referida pesquisa possui finalidade básica, de natureza observacional e abordagem quali-quantitativa. Quanto aos objetivos, caracteriza-se como exploratória, uma vez que buscou proximidade dos pesquisadores com o tema investigado. Quanto aos procedimentos técnicos, caracteriza-se como uma pesquisa de campo, uma vez que busca compreender os mais diferentes aspectos da realidade de preceptores vinculados ao programa Residência Pedagógica, ocorrendo integralmente de forma remota (Fontelles et al., 2009).

A pesquisa foi aplicada a professores da Educação Básica da Rede Pública de Ensino do Estado do Piaú́, que se encontram vinculados ao programa Residência Pedagógica na modalidade de preceptores, no âmbito do Instituto Federal do Piauí (PRP IFPI-2020/2022). Todo o contato aos docentes ocorreu de forma remota, em respeito às normas de distanciamento social, utilizando-se para isso o aplicativo de troca de mensagens WhatsApp.

No contato inicial aos preceptores, apresentamos os objetivos da pesquisa e posteriormente os convidamos a participar. A efetivação da participação ocorreu por meio da concordância a um Termo de Consentimento Livre e Esclarecido (TCLE). Esse documento garantiu entre outras coisas o anonimato das respostas dos participantes, a retirada dos dados a qualquer momento anterior à publicação, bem como a divulgação científica dos resultados coletados.

Para coleta de dados, utilizou-se um questionário semiestruturado produzido pela plataforma Google Forms, disponibilizado por meio de um link de acesso direto aos docentes participantes pelo aplicativo WhatsApp. O questionário foi subdividido em quatro seções, sendo a primeira responsável pela caracterização do perfil, a segunda seção relacionada à percepção dos preceptores quanto a realização do PRP, uma seção relacionada ao uso de tecnologias digitais no contexto educacional, e por fim uma seção relacionada aos sentimentos associados ao ensino remoto. 
Para análise dos dados, as respostas relacionadas às perguntas objetivas foram convertidas em porcentagens, realizandose para isso uma análise quantitativa. As perguntas abertas foram submetidas a uma análise de conteúdo voltada à manipulação do texto para interpretação e inferência dos sentidos, seguindo as recomendações de Ferreira \& Loguecio (2014), caracterizandose como uma análise qualitativa.

\section{Resultados e Discussão}

Participam do PRP-IFPI (2020-2022) na modalidade de Preceptor um total de 39 docentes alocados em 13 núcleos. A pesquisa contou com a participação de 28 preceptores, que representam $72 \%$ da amostra total do público-alvo. Dentre os participantes, 16 pertencem ao gênero feminino e 12 ao gênero masculino. A faixa etária dos indivíduos variou entre 28 e 52 anos com predominância de participantes com idade entre 39 e 49 anos (50\%). Em relação a área de atuação, oito participantes (28,6\%) atuam na área de biologia, oito $(28,6 \%)$ na área de matemática, cinco $(17,9 \%)$ na química, cinco $(19,9 \%)$ na física, e dois na área de informática $(7,2 \%)$. Quanto ao município que atuam como preceptores, oito $(28,6 \%)$ atuam em Teresina, cinco (17,9\%) em Floriano, quatro (14,3\%) em Picos, quatro (14,3\%) em Angical, três (10,7\%) em Uruçuí, dois em (Piripiri) e dois (7,1\%) no município de Parnaíba.

Sobre a formação continuada dos participantes, 20 (71,4\%) são especialistas, cinco $(17,9 \%)$ são mestres e três $(10,7 \%)$ não possuem formação continuada. Em relação a experiência docente, nove participantes $(32,2 \%)$ possuem mais de 20 anos de experiência, sete participantes (25\%) entre 11 e 15 anos de experiência, seis participantes $(21,4 \%)$ entre seis e 10 anos de experiência, cinco (17,9\%) entre 16 e 20 anos de experiência, e um $(3,6 \%)$ entre um e cinco anos de experiência.

Inicialmente, buscamos conhecer as percepções dos preceptores sobre o PRP, que vem ocorrendo integralmente de forma remota. Nesse sentido, na primeira pergunta os participantes foram questionados sobre a importância do programa para sua experiência profissional, sendo apresentadas as alternativas "muito importante", "pouco importante" e "sem importância". Nas respostas, todos marcaram a alternativa muito importante. Becker et al. (2020), ao realizarem um trabalho com preceptores do PRP no interior do Rio Grande do Sul, destacaram nos seus resultados a importância do programa para a formação continuada dos docentes, por ser um espaço que permite discussões e reflexões acerca da prática docente.

Na questão seguinte, perguntou-se aos preceptores a sua percepção em relação a qualidade de execução do Programa Residência Pedagógica (IFPI - 2020/2022) que vem ocorrendo integralmente de forma remota, 21 preceptores (75\%) afirmaram ser bom, seis $(21,4 \%)$ consideram excelente e apenas um $(3,6 \%)$ apontou a alternativa regular, como observado na Figura 1. Nesse contexto, Biazolli, Gregolin e Stassi-Sé (2021), ao realizarem um estudo em um subprojeto do núcleo de Letras do PRP, evidenciam que apesar do ensino presencial ser insubstituível, o ensino remoto vigente permitido pela estrutura institucionalizada do PRP, tem aproximado os atores da residência por meio das ferramentas digitais, bem como fornecem dados para melhorias no referido curso, evidenciando também qualidade em sua execução. 
Figura 1: Percepção dos participantes da pesquisa em relação a qualidade de execução do Programa Residência Pedagógica (IFPI - 2020/2022) que vem ocorrendo integralmente de forma remota.

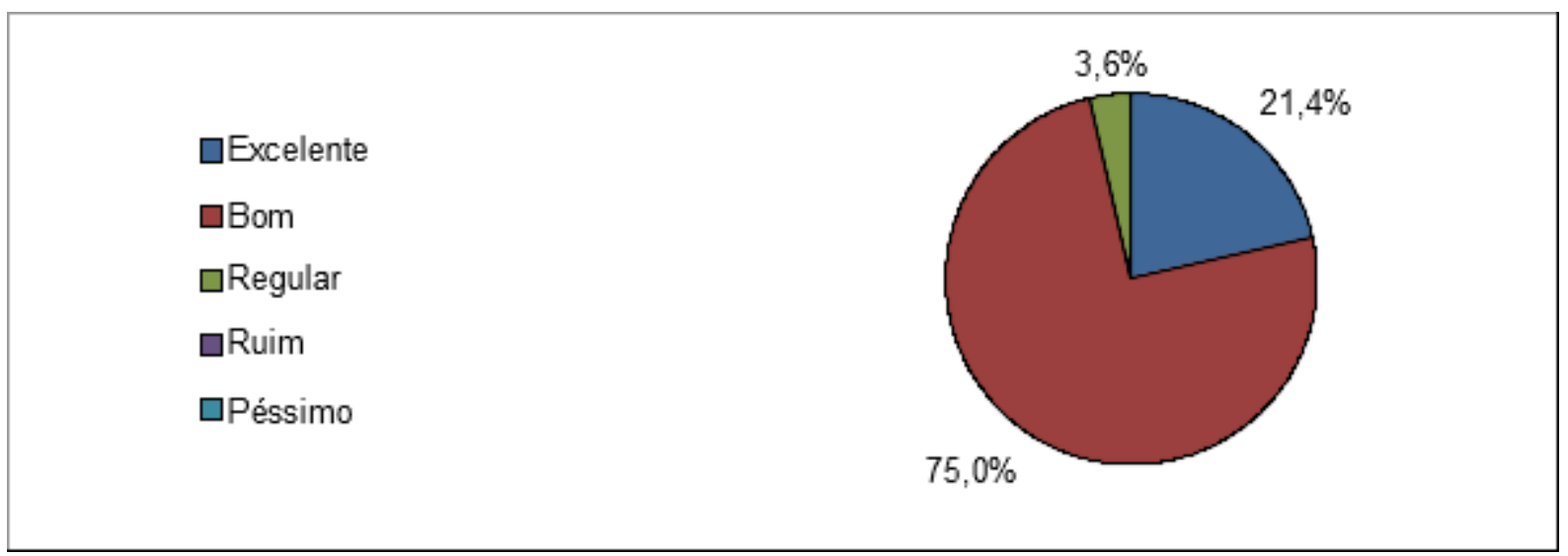

Fonte: Autores (2021).

Na pergunta três, os participantes foram questionados sobre a contribuição do programa Residência Pedagógica (IFPI 2020/2022) na qualidade do ensino nas escolas campo, nas respostas, 27 partícipes (96,4\%) afirmaram que o programa contribuiu bastante e um (3,6\%) acredita que o programa ao ser implementado de forma remota pouco contribuiu. Nascimento et al. (2021) afirma que o ensino remoto precisa ser visto como um leque de possibilidades e estímulo à pesquisa, de modo a enriquecer o processo de ensino-aprendizagem. No entanto, vale ressaltar que tal perspectiva é ainda mais complexa e precisa ser analisada de maneira abrangente, uma vez que inúmeras dificuldades vêm sendo enfrentadas pelos docentes.

A quarta questão indagou aos preceptores sobre sua preparação para orientar e acompanhar os residentes na execução de suas atividades por meio do ensino remoto. Nas respostas, 21 preceptores (75\%) acreditam estar em adaptação, pois foram pegos de surpresa pela nova realidade de ensino, cinco (17,9\%) se dizem muito bem preparados, pois já tinham determinada familiaridade com as tecnologias atualmente utilizadas, e apenas dois $(7,1 \%)$ afirmaram que continuam com dificuldades frente a essa nova modalidade, como observado na Figura 2. A adaptação evidenciada em nossos resultados deve ser encarada como um processo normal, tendo em vista a forma que o ensino remoto foi implementado, considerando a ausência de planejamento, ausência de capacitação e estruturação de condições e configurações mínimas de suporte para os envolvidos nessa modalidade de ensino (Silva, Sousa \& Menezes, 2020).

Figura 2 - Concepção dos preceptores do Programa Residência Pedagógica (IFPI - 2020/2022) quanto a preparação para orientar e acompanhar os residentes durante o período de ensino remoto.

口Estou em adaptação

Me sinto bem preparado

$\square$ Continuo com dificuldades

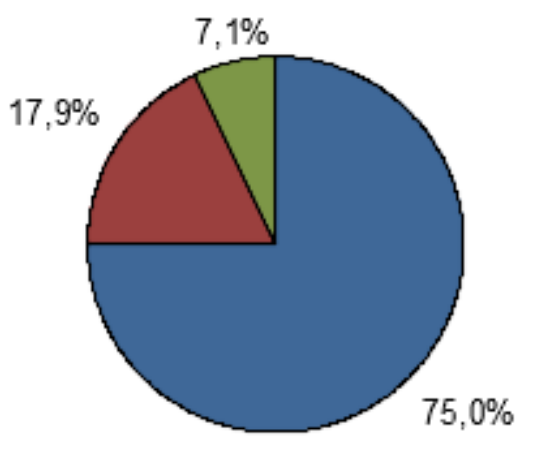


Os preceptores foram indagados na questão cinco sobre a sua principal dificuldade na orientação e acompanhamento nas atividades dos residentes. Dos 28 docentes participantes, 17 (60,7\%) não relataram dificuldades, e 11 (39,3\%) as apontaram, sendo elas: Realizar mudanças nas metodologias de ensino, apontada por cinco participantes; Fixar a atenção dos residentes nas atividades desenvolvidas, relatada por dois preceptores; Falar uma linguagem que contemple todos (um preceptor); Lidar com a falta de estímulo dos residentes para com as aulas remotas (um preceptor); Utilização das TICs (um preceptor); Avaliar o trabalho dos residentes (um preceptor), como observado na Tabela 1.

Tabela 1 - Principais dificuldades apontadas pelos preceptores do Programa Residência Pedagógica (IFPI - 2020/2022) em relação a orientação e/ou acompanhamento das atividades dos residentes.

\begin{tabular}{|c|c|c|}
\hline Categoria & Citações & Transcrição literal das falas dos participantes \\
\hline $\begin{array}{l}\text { Realizar mudanças nas } \\
\text { metodologias de ensino. }\end{array}$ & 5 & $\begin{array}{l}\text { "Estamos em adaptação pois, o programa era de forma presencial”. } \\
\text { "...tive que fazer algumas mudanças na metodologia de ensino, para que os } \\
\text { residentes conseguissem concluir as atividades da melhor forma possível...". } \\
\text { "Há princípio foi muito difícil devido a não experiência de se trabalhar com } \\
\text { ensino remoto...". } \\
\text { "...foi uma oportunidade para novos aprendizados e oportunidades, aqueles } \\
\text { que se adaptarem melhor terão um leque maior de oportunidades...". } \\
\text { "O desfio é grande, mas espero contribuir e muito com o preparo dos nossos } \\
\text { residentes e alunos da escola na qual eu trabalho". }\end{array}$ \\
\hline $\begin{array}{l}\text { Fixar a atenção dos residentes nas } \\
\text { atividades desenvolvidas }\end{array}$ & 2 & $\begin{array}{l}\text { "Dificuldade apenas em chamar a atenção dos alunos para participarem das } \\
\text { atividades da residência na forma remota". } \\
\text { "Uma dificuldade que tenho enfrentado é que alguns residentes (minoria) } \\
\text { recorrentemente não acompanham todas as postagens no grupo (áudios, msg } \\
\text { e vídeos tutoriais), e acabam me fazendo trabalhar duas vezes porque tenho } \\
\text { que repassar em particular informações simples como datas e itens a serem } \\
\text { entregues ou produzidos quando os prazos estão estourando". }\end{array}$ \\
\hline $\begin{array}{l}\text { Falar uma linguagem que } \\
\text { contemple todos. }\end{array}$ & 1 & $\begin{array}{l}\text { "A maior dificuldade é falar uma linguagem que atinge a todos, ou seja, as } \\
\text { vezes nem todos entendem da mesma forma o que deve ser feito". }\end{array}$ \\
\hline $\begin{array}{l}\text { Lidar com a falta de estímulo dos } \\
\text { residentes para com as aulas } \\
\text { remotas. }\end{array}$ & 1 & $\begin{array}{l}\text { "Outra dificuldade é lidar com a falta de estímulo dos residentes para com } \\
\text { as aulas remotas, muitas vezes por acharem que é esforço em vão". }\end{array}$ \\
\hline Utilização das TICs. & 1 & $\begin{array}{l}\text { "Todo o processo de acompanhamento aos residentes de forma remota, têm } \\
\text { algumas dificuldades, mas está ocorrendo com qualidade e tranquilo, temos } \\
\text { vários encontros remotos, planejamos e executamos às habilidades. } \\
\text { Dificuldades acontecem. Principalmente com as mídias, Internet. Mas tem } \\
\text { dado certo". }\end{array}$ \\
\hline Avaliar o trabalho dos residentes. & 1 & "Minha maior dificuldade é na hora de avaliar". \\
\hline Não apontaram dificuldades. & 17 & - \\
\hline Total & 28 & - \\
\hline
\end{tabular}

Fonte: Autores (2021).

Dificuldades também foram evidenciadas por Araújo et al. (2021) ao analisarem as condições objetivas e subjetivas vivenciadas por docentes universitários brasileiros frente ao trabalho remoto emergencial. Assim, dentre as dificuldades apontadas pelos autores e também evidenciadas nos nossos resultados, destacam-se: “a comunicação com colegas e alunos é 
muito prejudicada"; "não possuo domínio das ferramentas digitais. Então tudo é difícil, às vezes impossível”; "dificuldade em motivar os discentes [...], em criar avaliações".

Na questão seis, buscamos identificar o grau de dificuldade dos preceptores em relação ao uso dos recursos tecnológicos necessários para a realização do ensino remoto. Nas respostas, observamos que 22 preceptores (78,6\%) mencionaram apresentar pouca dificuldade com recursos tecnológicos, quatro $(14,3 \%)$ sentem muita dificuldade e dois $(7,1 \%)$ nenhuma dificuldade, como pode ser observado na Figura 3.

Figura 3: Grau de dificuldade dos preceptores do Programa Residência Pedagógica (IFPI - 2020/2022) em relação ao uso dos recursos tecnológicos necessários para a realização das atividades não presenciais.

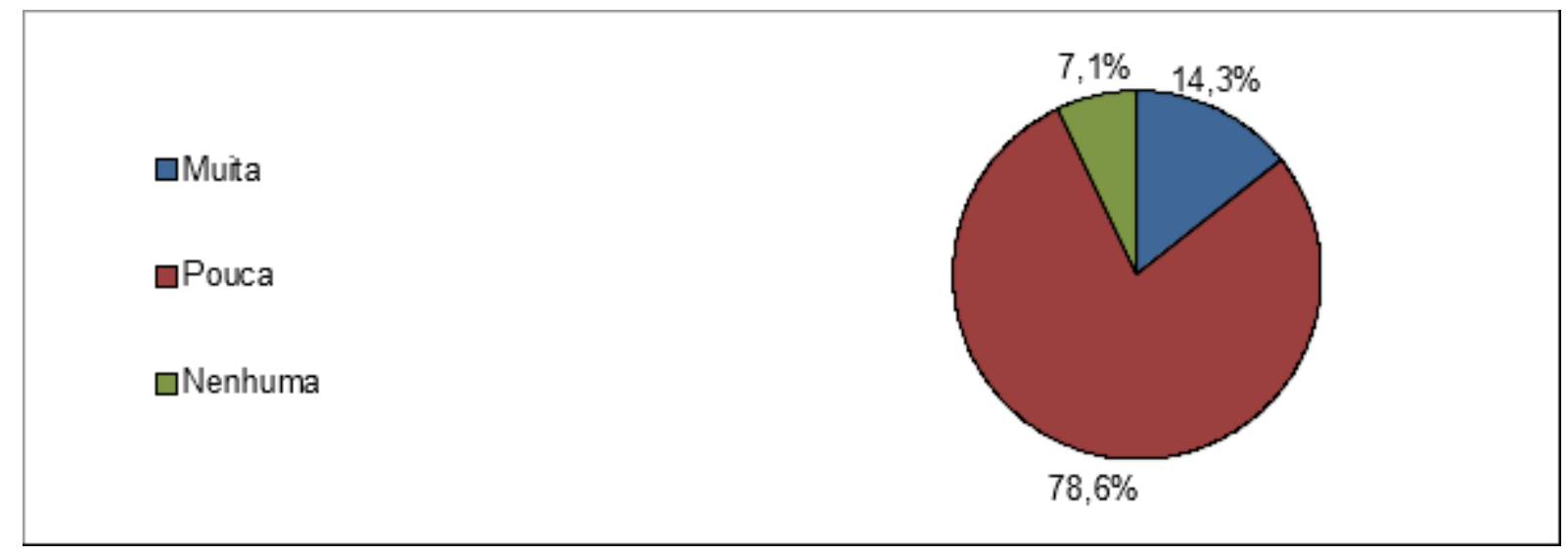

Fonte: Autores (2021).

Uma parcela significativa dos participantes possui muita dificuldade com a utilização de recursos tecnológicos nas aulas remotas, uma vez que as transformações no sistema educacional aconteceram de forma emergencial, exigindo dos docentes uma rápida adaptação das aulas presenciais para plataformas online com a incorporação das Tecnologias Digitais da Informação e Comunicação (TDIC) (Rondini, Pedro \& Duarte, 2020). Ressaltamos que nem todos os profissionais da educação detinham de habilidades e preparação para utilização desses recursos que muitas vezes são poucos utilizados no ambiente escolar, como destaca Almeida et al. (2020), ao afirmarem que existe uma carência de formação tecnológica nas instituições brasileiras, tornando a incorporação das TDIC nas aulas uma barreira.

$\mathrm{Na}$ questão sete, perguntou-se aos preceptores quais as principais tecnologias digitais utilizadas pelos preceptores e seus residentes durante as aulas remotas, foram observadas: a utilização do aplicativo de mensagens WhatsApp por todos os participantes, seguido da plataforma Google Meet por 27 (96,4\%), posteriormente o YouTube por 24 (85,7\%) e o Google Forms utilizado por $23(82,1 \%)$ dos preceptores. Outras ferramentas são também utilizadas, mas com menor frequência, como se observa na Figura 4. 
Figura 4 - Principais tecnologias digitais utilizadas pelos preceptores e residentes do Programa Residência Pedagógica (IFPI 2020/2022) para realização do ensino remoto.

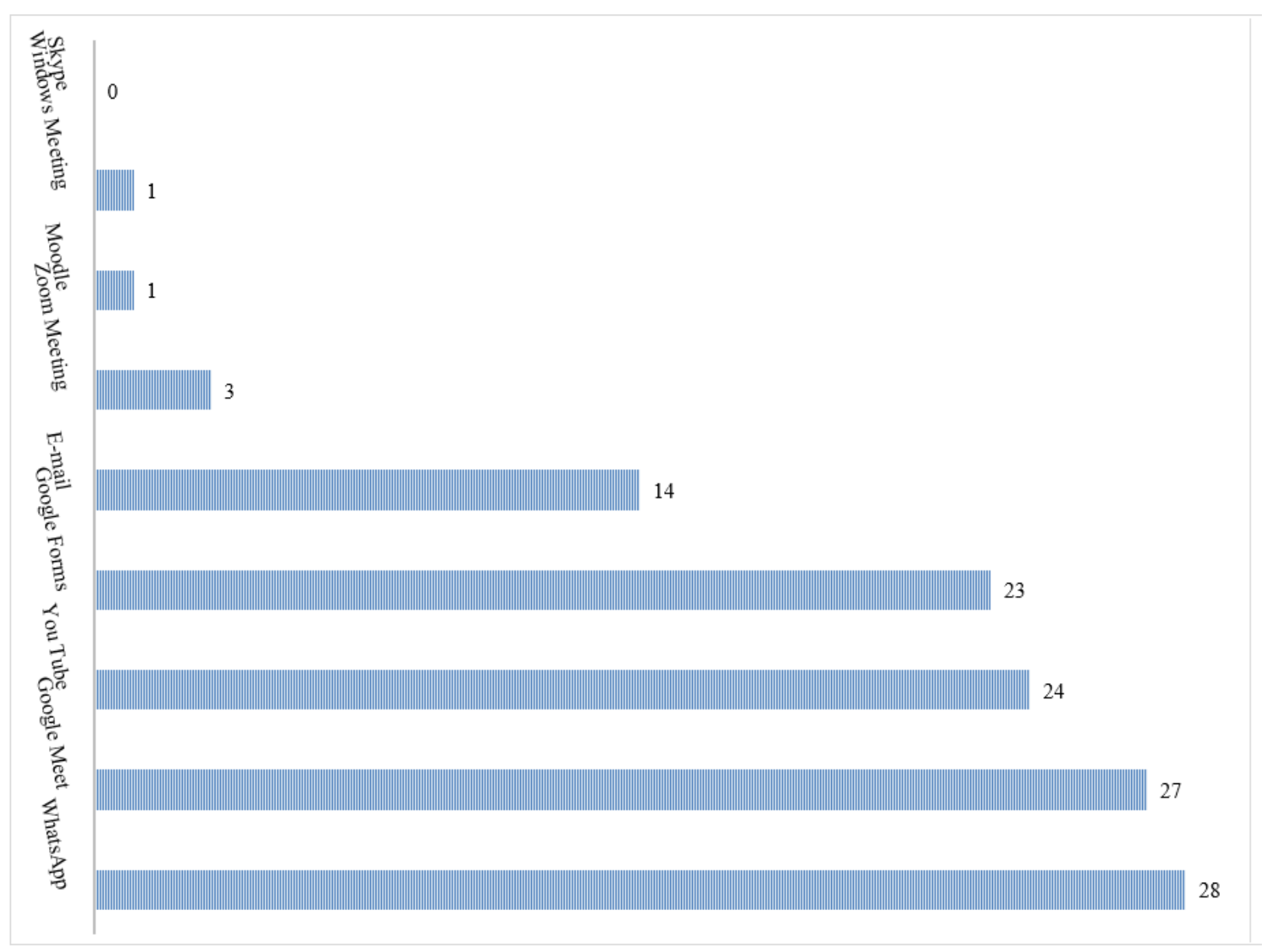

Fonte: Autores (2021).

Moreira, Henriques e Barros (2020) destacam que os estudantes geralmente preferem se comunicar por meio de aplicativos mais informais e do seu cotidiano como, a exemplo o WhatsApp. Tal preferência pode estar ligada a sua praticidade e acessibilidade, se transformando em uma ferramenta complementar e potente para tirar dúvidas sobre conteúdos e até mesmo sobre as próprias tecnologias adotadas pela instituição de forma instantânea, além da facilidade na troca de informações através de elementos visuais que servem como base para conhecimento que está sendo debatido (Hallwass \& Bredow, 2021).

O período de aulas remotas provocou mudanças no processo de ensino e aprendizagem exigindo adaptações de todos os envolvidos, inclusive os docentes. Aliado ao processo adaptativo existia ainda a preocupação de todos com a pandemia do novo Coronavírus. Diante desse cenário, buscamos também identificar a percepção dos preceptores em relação a sua felicidade. Nas respostas, 26 participantes $(92,8 \%)$ mencionaram se sentir mais felizes antes da pandemia, um (3,6\%) relatou não perceber diferença no seu nível de felicidade, e um $(3,6 \%)$ mencionou sentir-se mais feliz no período atual em comparação ao anterior a pandemia, como observado na Figura 5. 
Figura 5 - Percepção dos preceptores do Programa Residência Pedagógica (IFPI - 2020/2022) em relação a sua felicidade no momento atual e anterior a pandemia.

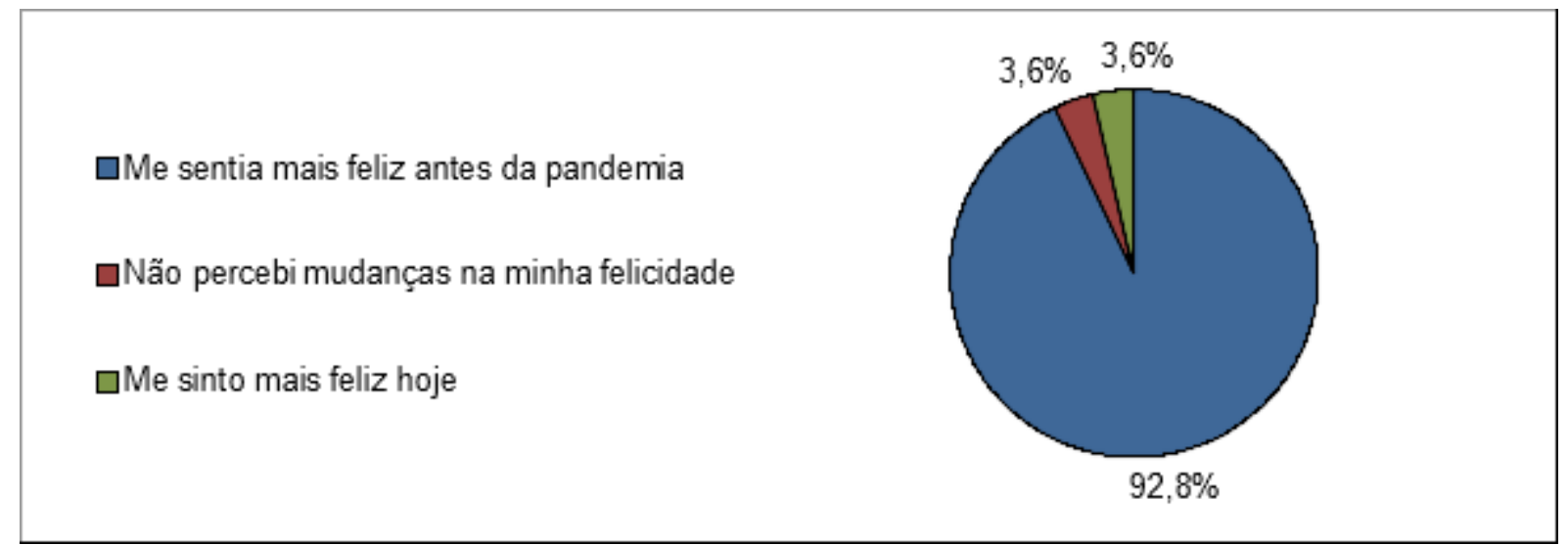

Fonte: Autores (2021).

Como observado, maior parte dos preceptores se sentiam mais felizes antes da pandemia, mostrando que esse período afetou de forma direta o emocional dos participantes. Ao analisar a satisfação de 56 professores pertencentes aos Estados de São Paulo e Paraíba, Lima (2020) constatou que 96,5\% dos docentes afirmaram se sentirem mais felizes antes da pandemia, em detrimento a 3,5\%, que afirmaram continuar com tal satisfação. Resultados semelhantes também foram observados por Silva, Braga e Mello (2021), os quais investigaram a formação pedagógica em tempos de distanciamento social, ficando claro em seus resultados que a pandemia afetou totalmente a condição socioemocional de $65,4 \%$ dos participes.

Na pergunta nove, os participantes foram questionados sobre o tipo de sentimento que eles apresentavam para o ensino remoto, e os resultados mostraram que 10 preceptores $(35,7 \%)$ sentiam ansiedade, nove $(32,1 \%)$ insatisfação, seis $(21,4 \%)$ estresse, dois $(7,2 \%)$ angústia e um $(3,6 \%)$ tristeza. As alternativas relaxamento, satisfação e alegria não foram apontadas pelos preceptores, como está evidenciado na Figura 6. No contexto da pandemia da COVID-19, alguns autores (Brooks et al., 2020; Qiu et al., 2020; Santana et al., 2020 \& Van-Bavel et al., 2020) apontam que sentimentos como ansiedade estresse, angústia e tristeza estão relacionados à duração do isolamento social, de modo que a soma desses sentimentos pode ser atribuída a alguns fatores como o medo de contrair a doença, a preocupação com a própria saúde e de entes queridos. Borba et al. (2020) ainda destacam o acúmulo de tarefas que contribui de forma negativa para o sentimento de insatisfação.

Figura 6 - Sentimento apresentado pelos perceptores do Programa Residência Pedagógica (IFPI - 2020/2022) após a implementação do ensino remoto.

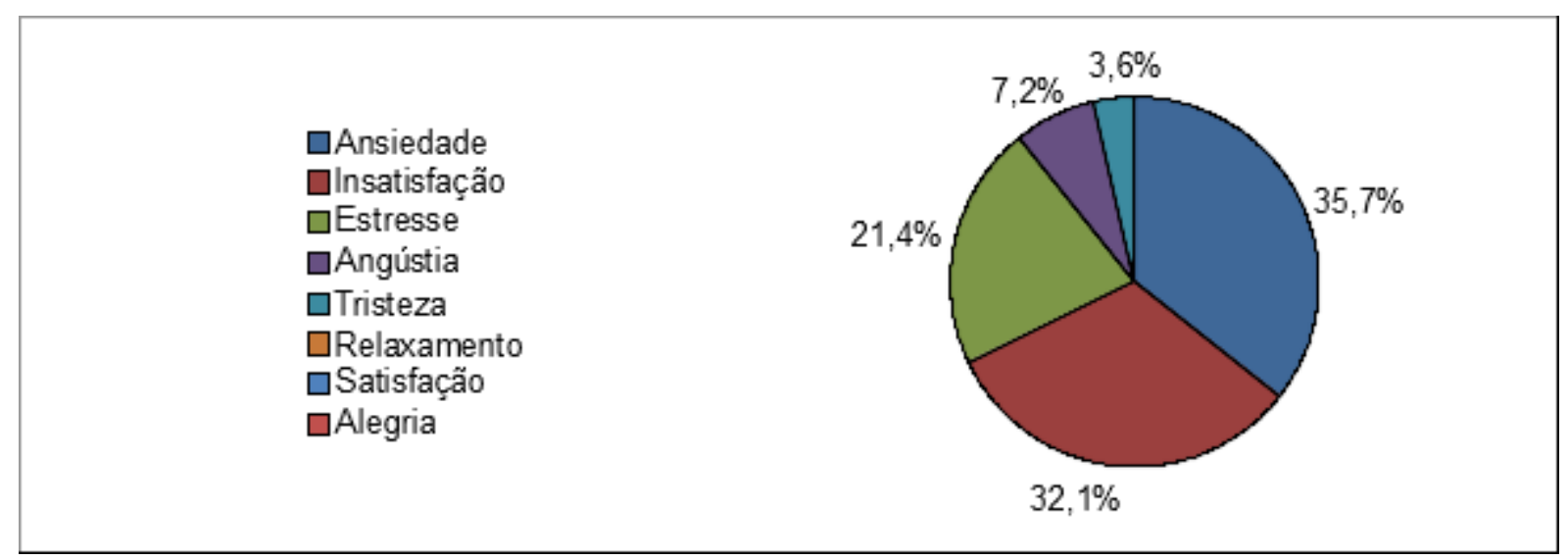

Fonte: Autores (2021). 
Ao serem perguntados na questão seguinte sobre o nível de estresse relacionado ao trabalho como docente no ensino remoto, 15 participantes $(53,6 \%)$ mencionaram ser muito estressante, nove $(32,1 \%)$ apontaram ser pouco estressante, dois $(7,1 \%)$ relataram que a forma presencial causava mais estresse, um $(3,6 \%)$ apontou que o estresse causado pela forma presencial e remota é a mesma, e um preceptor (3,6\%) disse não causar estresse, como observado na Figura 7. Paulo, Araújo e Oliveira (2020) destacam que a sobrecarga gerada pelo acúmulo de trabalho e o desgaste emocional relacionado ao tempo vivido pode acarretar ansiedade e estresse aos docentes, como constatamos em nosso trabalho.

Figura 7 - Percepção dos preceptores do Programa Residência Pedagógica (IFPI - 2020/2022) em relação ao estresse relacionado ao trabalho docente.

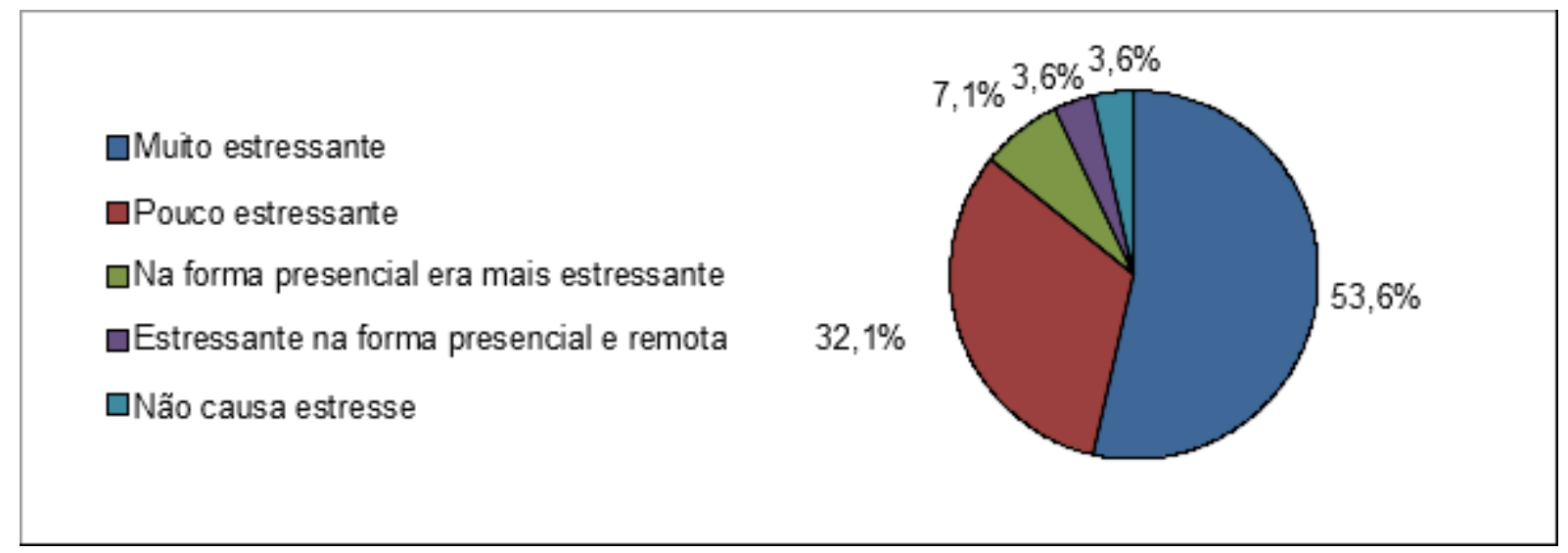

Fonte: Autores (2021).

A questão 11 indagou aos preceptores sobre sua demanda de trabalho no ensino remoto em comparação ao ensino presencial. Nas respostas, 23 participantes $(82,1 \%)$ mencionaram que a demanda aumentou, três $(10,7 \%)$ não perceberam diferenças na demanda, e dois (7,2\%) relataram ter diminuído, como observado na Figura 8. Borba et al. (2020) apontam que os docentes têm esse sentimento de aumento de carga horária devido principalmente à ausência de formação técnica necessária para o ensino remoto, e dessa forma o tempo de planejamento das aulas acaba se prolongando.

Figura 8 - Percepção dos preceptores do programa Residência Pedagógica (IFPI - 2020/2022) em relação à sua demanda de trabalho na comparação do período atual com o anterior a pandemia.

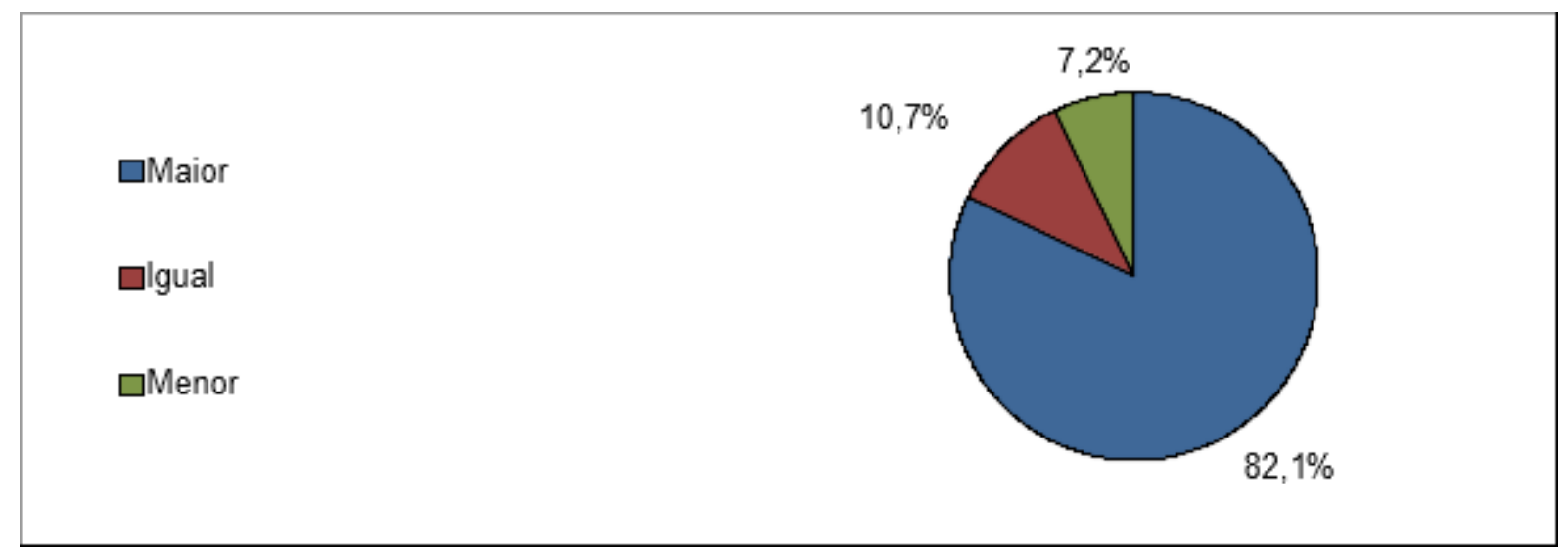

Fonte: Autores (2021).

Os participantes foram indagados na questão 12 sobre as principais dificuldades nesse momento de ensino remoto. Nas respostas, $16(57,1 \%)$ apontaram a falta de interação com alunos e acompanhamento pedagógico, sete $(25 \%)$ mencionaram 
a carga horária elevada, três $(10,7 \%)$ relataram dificuldade em encontrar um local adequado para preparar e gravar aulas, um $(3,6 \%)$ identificou a ministração de aulas preocupados com a saúde da família, um $(3,6 \%)$ identificou a necessidade de utilizar diversas estratégias de ensino, como observado na Figura 9.

Figura 9 - Principais dificuldades apontadas pelos preceptores do Programa Residência Pedagógica (IFPI - 2020/2022) no contexto de ensino remoto.

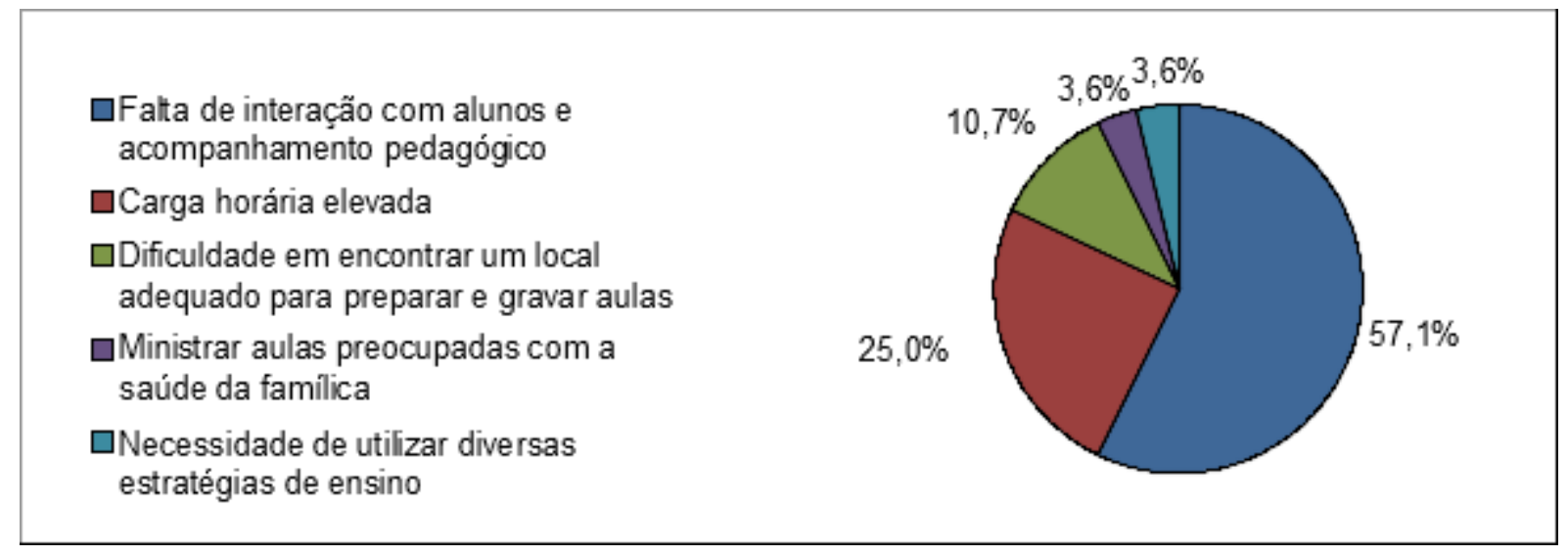

Fonte: Autores (2021).

A falta de interação com os alunos e acompanhamento pedagógico se mostrou como a maior dificuldade para os preceptores participantes desse trabalho no contexto do ensino remoto. Schmitt, Bugalho e Kruger (2021), ao realizarem um trabalho com docentes de instituições de ensino superior no que tange ao processo de ensino-aprendizagem durante o isolamento social, também constataram, dentre as maiores dificuldades apuradas, a interação com os alunos, apontada por 33\% de seu grupo amostral. A segunda dificuldade que mais foi apontada em nosso estudo está relacionada ao aumento da carga horária. Nessa perspectiva, Santos e Zaboroski (2020), durante o desenvolvimento de uma revisão detalhada em livros, sites e outros veículos de comunicação sobre os desafios trazidos pelo novo coronavírus no contexto educacional, destacaram que os docentes têm que conciliar a vida profissional com as atribuições da vida pessoal, o que gera sobrecarga de trabalho e só aumentou com a pandemia.

Em seguida, os preceptores foram questionados sobre sua preparação para as aulas presenciais frente aos aprendizados obtidos na pandemia. Nas respostas, 25 preceptores $(89,3 \%)$ afirmaram sentirem-se mais preparados para o retorno das aulas presenciais a partir dos aprendizados obtidos no ensino remoto, e três (10,7\%) apontaram que não. Almeida et al. (2020), ao realizarem uma pesquisa bibliográfica qualitativa sobre a postura docente diante do ensino remoto e em pós-pandemia, apontam que o cenário de isolamento social estimulou os docentes a se reinventar e adaptar sua metodologia de ensino com o uso das tecnologias ao mesmo tempo que despertou a utilização desses novos métodos no período pós-pandêmico.

$\mathrm{Na}$ última questão, os preceptores foram indagados se pretendem realizar mudanças metodológicas nas suas aulas presenciais tendo em vista os aprendizados docentes obtidos no período de pandemia. Observamos que todos os partícipes percebem a necessidade de inovação e de mudanças metodológicas, tendo em vista a melhoria do processo de ensino e aprendizagem. Para Barros et al. (2021), as escolas da atualidade requerem cada vez mais do docente uma mente aberta para as mudanças, e apontam a necessidade de serem inovadores e capazes de estimular os alunos a aprendizagem. Verificamos então que o período remoto trouxe oportunidades diversas de novos aprendizados e vivências que estimularam a reflexão e a autocrítica aos professores. 


\section{Conclusão}

O ensino remoto emergencial imposto pelo cenário pandêmico, trouxe dificuldades diversas ao campo educacional, exigindo a adaptação rápida de todos os envolvidos nesse processo. E foi nesse contexto, que de forma assertiva se deu o início do Programa Residência Pedagógica IFPI (2020-2022), objetivando o estímulo a experiência de regência em sala de aula, como parte fundamental à formação docente. Apesar da necessidade constante de ajustes, todos os preceptores participantes da pesquisa consideram a execução do programa muito importante, mesmo que de forma remota, e a maioria julga sua execução no âmbito do Instituto Federal do Piauí, boa ou excelente.

Apesar dos preceptores participantes relatarem novas aptidões e habilidades a partir das vivências que vêm ocorrendo pelo PRP (IFPI-2020/2022), observamos como barreiras a falta de interação com os alunos da educação básica e a carga horária docente intensificada em virtude das atividades remotas. Apontamos também que os docentes associam sentimentos de ansiedade, insatisfação e estresse ao ensino remoto, e que no momento da pesquisa se sentiam menos felizes em comparação ao período anterior a pandemia. Nessa conjuntura, ressaltamos a necessidade de um acompanhamento multiprofissional aos docentes no período atual, bem como destacamos a necessidade da realização de mais estudos que nos permitam estimar o impacto da pandemia no processo de ensino aprendizagem ocorrido nas escolas, bem como ao bem estar dos envolvidos.

\section{Agradecimentos}

Agradecemos a Coordenação de Aperfeiçoamento de Pessoal de Nível Superior (CAPES) pelo suporte ao Programa Residência Pedagógica, e pelo estímulo a integração entre educação básica e superior. Agradecemos também ao Instituto Federal do Piauí (IFPI) em nome do professor Valtercio de Almeida Carvalho pelo apoio irrestrito, e por proporcionar as condições necessárias ao bom desenvolvimento do programa. Por fim, agradecemos à todos os preceptores que disponibilizaram seu valioso tempo para participação dessa pesquisa.

\section{Referências}

Almeida, E. G., Leite, K. L. F., Ferreira, L. S., \& Farias, M. S. (2020). Ensino remoto e tecnologia: uma nova postura docente na educação pós-pandemia. Congresso Nacional de Educação, 7(1), 1-10. https://editorarealize.com.br/editora/anais/conedu/2020/TRABALHO_EV140_MD1_SA1 9_ID4391_02092020001229.pdf

Appenzeller, S., Menezes, F. H., Santos, G. G. D., Padilha, R. F., Graça, H. S., \& Bragança, J. F. (2020). Novos tempos, novos desafios: estratégias para equidade de acesso ao ensino remoto emergencial. Revista Brasileira de Educação Médica, 44 (1), 1-6. https://www.scielo.br/j/rbem/a/9k9k dKQsPSDPMsP4Y3XfdL/?lang=pt

Araújo, M. D. P. N., Barroso, R. D. R. F., Machado, M. L., de Magalhães Cunha, C., de Oliveira Queiroz, V. A., Martins, P. C., \& Santana, M. L. P. (2021). Residência é residência, trabalho é trabalho: estudo quali-quantitativo sobre o trabalho remoto de professores universitários durante a pandemia da COVID-19. Research, Society and Development, 10(9), 1-16. https://rsdjournal.org/index.php/rsd/article/download/18068/16089/225838+\&cd=1\&hl=pt$\mathrm{BR} \& \mathrm{ct}=\mathrm{clnk} \& \mathrm{gl}=\mathrm{br}$

Barros, C. C. A., Souza, A. da S., Dutra, F. D., Gusmão, R. S. C., \& Cardoso, B. L. C. (2021). Precarização do Trabalho Docente: reflexões em tempos de pandemia e pós pandemia. Ensino Em Perspectivas, 2(2), 1-23. https://revistas.uece.br/index.php/ensinoemperspectivas/article/view/4975

Becker, E. P., Sawitzki, R. L., Callai, A. N. A., \& Borck, M. P. (2021). A relação entre o Programa Residência Pedagógica e a Formação Continuada de Professores Preceptores. Iniciação \& Formação Docente, 7(4), 969-980. http://seer.uftm.edu.br/revistaeletronica/index.php/revistagepadle/article/view/4313

Bernard, R. M., Abrami, P. C., Borokhovski, E., Wade, C. A., Tamim, R. M., Surkes, M. A., \& Bethel, E. C. (2009). A meta-analysis of three types of interaction treatments in distance education. Review of Educational research, 79(3), 1243-1289. https://www.researchgate.net/publication/249798035_A_MetaAnalysis_of_Three_Types_of_Interaction_Treatments_in_Distance_Education

Biazolli, C. C., Gregolin, I. V., \& Stassi-Sé, J. C. (2021). Contribuições do Programa Residência Pedagógica à formação inicial de futuros professores de línguas: aspectos da parceria colaborativa. Formação Docente-Revista Brasileira de Pesquisa sobre Formação de Professores, 13(26), 155-170. https://revformacaodocente.com.br/index.php/rbpfp/article/view/420

Borba, R. C. N., Teixeira, P. P., Fernandes, K. D. O. B., Bertagna, M., Valença, C. R., \& Souza, L. H. P. (2020). Percepções docentes e práticas de ensino de ciências e biologia na pandemia: uma investigação da Regional 2 da SBEnBio. Revista de Ensino de Biologia- REnBio, 13(1), 153171. https://sbenbio.journals.com.br/index.php/sbenbio/article/view/337

Brasil. (2018). Coordenação de Aperfeiçoamento de Pessoal de Nível Superior. Edital 6/2018: Chamada Pública para apresentação de propostas no âmbito do Programa de Residência Pedagógica. https://www.gov.br/capes/pt-br/centrais-de-conteudo/01032018-edital-6-2018-residencia-pedagogica-pdf 
Brasil. (2020). Coordenação de Aperfeiçoamento de Pessoal de Nível Superior. Edital 1/2020: Chamada Pública para apresentação de propostas no âmbito do Programa de Residência Pedagógica. https://www.gov.br/capes/pt-br/centrais-de-conteudo/06012020-edital-1-2020-residencia-pedagogica-pdf

Brasil. (2019). Portaria n 259, de 17 de dezembro de 2019. Dispõe sobre o regulamento do Programa de Residência Pedagógica e do Programa Institucional de Bolsa de Iniciação à Docência (PIBID). Brasília. DOU - Diário Oficial da União. https://www.in.gov.br/en/web/dou/-/portaria-n-259-de-17-dezembro-de-2019234332362

Brooks, S. K., Webster, R. W., Smith, L. E., Woodland, L., Wessely, S., Greenberg, N., \& Rubin, G. J. (2020). The psychological impact of quarantine and how to reduce it: rapid review of the evidence. The Lancet, 395(10227), 912-920. https://www.thelancet.com/journals/lancet/article/PIIS0140-6736(20)304608/fulltext

Ferreira, M., \& Loguercio, R. Q. (2014). A análise de conteúdo como estratégia de pesquisa interpretativa em educação em ciências. Revista de Educação, Língua e Literatura. 6(2), 33-49. https://lume.ufrgs.br/bitstream/handle/10183/142567/000994515.pdf?sequence=1\&isAllowed=y

Fontelles, M. J., Simões, M. G., Farias, S. H., Fontelles, R. G. S. (2009). Scientific research methodology: Guidelines for elaboration of a research protocol. Revista Paraense de Medicina, 23(3), 1-8. https://pesquisa.bvsalud.org/portal/resource/pt/lil-588477

Godoi, M., Kawashima, L. B., Gomes, L. A. \& Caneva, C. (2020). O ensino remoto durante a pandemia de covid-19: desafios, aprendizagens e expectativas dos professores universitários de Educação Física. Research, Society and Development, 9(10), 1-19. https://www.researc hgate .net/publication/344485419_O_ensino_remoto_durante_a_pandemia_de_covid-19_desafios_aprendizagens_e_ex pectativas_dos_professores_universita rios_de_Educacao_Fisica

Hallwass, L. C. L., \& Bredow, V. H. (2021). WhatsApp como ambiente de interação social e aprendizagens durante o ensino remoto emergencial. Revista Educação e Emancipação, 14(2), 62-83. http://www.periodicoseletronicos.ufma.br/index.php/reducacaoemancipacao/article/view/17128

Hodges, C., Moore, S., Lockee, B., Trust, T., \& Bond, A. (2020). The difference between emergency remote teaching and online learning. Educause review, 27(1), 1-9. https://er.educause.edu/articles/2020/3/the-difference-between-emergency-remote-teaching-and-online-learning

Lima, M. R. L. D. (2020). A relação afetiva entre professor e aluno: a concepção de professores antes e durante a pandemia de Covid 19. In Universidade Federal da Paraíba, CE - TCC - Pedagogia à distância (paginação irregular). Paraíba: UFPB. https://repositorio.ufpb.br/jspui/handle/123456789/17889

Moreira, J. A., Henriques, S., \& Barros, D. M. V. (2020). Transitando de um ensino remoto emergencial para uma educação digital em rede, em tempos de pandemia. Dialogia, 351-364. https://www.researchgate.net/publication/340535196_The_Difference_Between_Emergency_Remote _Teaching_and_Online_Learning

Nascimento, E. R., Sudério, F. B., \& Paula Santos, C. (2021). Regências de biologia no ensino remoto emergencial: uma experiência no programa residência pedagógica. Conexão ComCiência, 1(3). https://revistas.uece.br/index.php/conexaocomciencia/article/view/5381

Oliveira, S. B. S. D., \& Madureira, L. C. (2020). Ensino remoto emergencial: guia prático de orientação aos docentes da Famed. Diamantina: UFVJM. http://acervo.ufvjm.edu.br:8080/jspui/bitstream/1/2274/1/guia_orient_docente_famed.pdf

Paulo, J.R., Araújo, S.M.M.S., Oliveira, P.D. (2020). Ensino remoto emergencial em tempos de pandemia: tecendo algumas considerações. Dialogia, (36), 193204. https://periodicos.uninove.br/dialogia/article/view/18318

Qiu, J., Shen, B., Zhao, M., Wang, Z., Xie, B., \& Xu, Y. (2020). A nationwide survey of psychological distress among Chinese people in the COVID-19 epidemic: implications and policy recommendations. Psiquiatria geral, 33 (2). https://gpsych.bmj.com/content/33/2/e100213

Rondini, C. A., Pedro, K. M., \& Santos Duarte, C. (2020). Pandemia do Covid-19 e o ensino remoto emergencial: Mudanças na práxis docente. Interfaces Científicas-Educação, 10(1), 41-57. https://periodicos.set.edu.br/educacao/article/view/9085

Rosseto, L. P., Labre, L. V. Q., Costa Monteiro, M. H., Silva, M. A., Segati, K. D., de Oliveira, R. R., Oliveira, R. F., Moura, R. S., Morgado, W. F. F., \& Santos Costa, W. (2020). Relatos de experiências de professores do nível superior no processo de ensino-aprendizagem durante a pandemia Covid-19. Trabalho apresentado no $39^{\circ}$ Seminário de Atualização de Práticas Docentes, 2(2), 1-6. http://anais.unievangelica.edu.br/index.php/praticasdocentes/article/view/5788

Santana, V. V. R. S., Nascimento, R. Z., Lima, A. A., \& Nunes, I. C. M. (2020). Alterações psicológicas durante o isolamento social na pandemia de covid-19: revisão integrativa. Revista Família, Ciclos de Vida e Saúde no Contexto Social, 2, 754-762. http://seer.uftm.edu.br/revistaeletronica/index.php/refacs/article/view/4706

Santos, J. R., \& Zaboroski, E. (2020). Ensino Remoto e Pandemia de COVID-19: Desafios e oportunidades de alunos e professores. Interacções, $16(55), 41-57$. https://revistas.rcaap.pt/interaccoes/article/view/20865

Schmitt, D. C., Bugalho, D. K., \& Kruger, S. D. (2021). Percepções docentes e às estratégias de ensino-aprendizagem durante o isolamento social motivado pelo COVID-19. Revista Catarinense da Ciência Contábil, 20(1), 1-19. https://revista.crcsc.org.br/index.php/CRCSC/article/view/3133/2253

SEDUC. (2020). Portaria ${ }^{\circ}$ 503/2020, de 10 de julho de 2020. Estabelece a alteração no calendário escolar 2020 em decorrência da pandemia Covid-19. Piauí: Secretaria de Estado da Educação. https://www.canaleducacao.tv/arquivos/normativa-documento/bddc5ffa71a94669f2cd3f775f7bc21c.pdf

Silva, A. C. O., Sousa, S. A., Menezes, J. B. F. (2020). O ensino remoto na percepção discente: desafios e benefícios. Dialogia, (36), 298-315. https://periodicos.uninove.br/dialogia/article/view/18383

Silva, A. R. N., Braga, F. M., \& de Mello, R. R. (2021). Formação pedagógica em aprendizagem dialógica em tempos de distanciamento social. Humanidades \& Inovação, 8(40), 252-268. https://revista.unitins.br/index.php/humanidadeseinovacao/article/view/5102

Souza, E. M. F, \& Ferreira, L. G. (2020). Ensino remoto emergencial e o estágio supervisionado nos cursos de licenciatura no cenário da Pandemia COVID 19. Revista Tempos e Espaços em Educação, 13(32), 1-20. https://dialnet.unirioja.es/servlet/articulo?codigo=7641432 
Research, Society and Development, v. 10, n. 11, e75101119359, 2021

(CC BY 4.0) | ISSN 2525-3409 | DOI: http://dx.doi.org/10.33448/rsd-v10i11.19359

Souza, V. G. R., Taborda, J. C., \& Freitas, C. J. (2021). Desgaste da saúde mental do docente da educação básica no interior do Mato Grosso do Sul. Humanidades \& Inovação, 8(41), 79-88. https://revista.unitins.br/index.php/humanidadeseinovacao/article/view/5101

Van-Bavel, J. J., Boggio, P. S., Capraro, V., Cichocka, A., Cikara, M., Crockett, M. J., \& Willer, R. (2020). Using social and behavioural science to support COVID-19 pandemic response. Nature human behaviour, 4(5), 460-471. https://www.nature.com/articles/s41562-020-0884-z 